\title{
Architecture of small Ukrainian and Mexican schools between XIX-XX centuries
}

\author{
Mariia Veres ${ }^{1,}$, and Olena Oliynyk ${ }^{2}$ \\ ${ }^{1}$ Kiev National University of Civil Engineering and Architecture, 03680, 31 Povitroflotsky Avenue, \\ Kyiv, Ukraine \\ ${ }^{2}$ National Aviation University, 03680, 1 Komarova avenue, Kyiv, Ukraine
}

\begin{abstract}
This article reports scientific and typological analysis of Ukrainian and Mexican architecture of small school buildings of the late XIX - early XX centuries in domestic art criticism in the context of comparative analysis. It analyzes national examples of small school buildings of Ukraine and Mexico which are of primary importance for understanding the architectural and artistic processes which took place in our territories at the end of the XIX - early XX centuries. The requirements that were met by this new architecture were significant progress in construction that addressed social needs through school buildings that allowed political action of the new regime. A new, relevant system was formed in the context of education policy and the pedagogical program, which justified its use in the post-revolutionary movement. Therefore, construction projects took into account the needs of working classes, agricultural and urban population. In these projects, interiors and typical designing of preschool areas are provided, advanced engineering, constructive and hygienic solutions are used, therefore they are a rather interesting phenomenon of Ukrainian and Mexican architectural design and are of great significance for the world architectural history.
\end{abstract}

\section{Introduction}

This paper investigates the formation of architecture of small schools in Ukraine and Mexico at the end of the XIX - early XX centuries. This issue was an integral part of the study in the general analysis of Mexican and Ukrainian authors throughout the XX century and was solved in other aspects, mainly historical.The architecture of small school buildings of Ukraine was analyzed in the scientific works of Shuldan L.A., Stitender A.Y., Kovalskyi L.M. and others. In scientific researches of various aspects and publications on the architecture of Ukrainian small schools, the question of the history of their creation and development was studied by Sleptsov O.S. and others to a degree. The authors refer to the works of Chepelyk V.V., Aleshin P.F., Khank V. M., Gradov G. A., Stepanov V. M., Zakharievich Y. and other researchers.

The history of Mexican school architecture has been extensively researched in periodicals of Mexico and in foreign works around the world. These include, in particular,

\footnotetext{
*Corresponding author: maryveresart@gmail.com
} 
the works of Axel Arano, Alegna, Paula, Natalia de la Rosa, José Miguel Gonzàlez, Gómez, Lilia and Miguel Angela de Quevedo and others. However, in the national practice, the theme of the architectural heritage of small schools of Mexico in the late XIX - early XX centuries remains without consideration of Ukrainian scientists.

\section{Article purposes}

To synthesize the experience of Ukraine and Mexico in the architecture and design of small schools and surroundings and analyze typological features of small schools, on the examples of the works of leading Ukrainian and Mexican architects. To consider the main features of planning schemes of small schools.

\section{The main part}

Public schools of Ukraine and Mexico were formed in the late XIX - early XX centuries under the conditions of national revival movements.

In the wake of the revolutionary revolt in Ukraine on October 17, 1905, Nicholay II signed a constitutional manifesto on political freedoms. The Ministry of Education received a permission to make some changes to the curriculum of secondary schools, to open new schools and increase the amount of appropriations for education.

The development of Ukrainian culture in the late XIX century occurred in the conditions of colonial political regimes. There was lack of primary and secondary schools. Education in Ukraine, which was a part of Russia, especially primary education, had been declining until the abolition of serfdom in the Russian Empire (1861). The tsarist government almost completely stopped financing primary schools. Only in the $1860 \mathrm{~s}$, young scientists, who united into a community, were actively engaged in the creation of Sunday schools. There were more than 110 of them in Ukraine in 1862, but in the same year the tsarist government decided to close Sunday schools and many of the organizers and teachers of these schools were arrested.

There was Mexican revolution in education at the same time. One of the most relevant and constructive goals of the Mexican revolution was specifically construction of schools. An ambitious educational program which would significantly reduce illiteracy was proposed. Two tasks were identified as urgent: to provide education in all parts of the republic through actions of teachers; to build as many schools using available resources as possible. This work was challenging and has been in progress ever since [1].

Ukrainian schools were located in monastery buildings and at churches until 1860s. In some richer villages, special buildings were under construction, but they didn't meet proper conditions. Most of the classes took place in dark cramp houses which were not adapted for educational process.

Spaces which were created during the period of the late XIX - early XX centuries in Mexico largely elaborated the great revolutionary ideals, and their realization was organized by some of the leading intellectuals of Mexico during that period, such as Jose Vasconcelos and Jaime Torres Bodet, who organized some of the building programs of the most successful schools, in intellectual collaboration with such intellectual collaborators as Carlos Obregon Santachilia, Guillermo Zararaga, Juan O'Gorman and Pedro Ramirez Vasquez. The experience gained in this architectural genre and the further technological development in the construction of these spaces has been exported to other countries and won worldwide recognition [2].

By that time, the schools were located in private homes which were rented for that purpose or in former monasteries. However, in passing to modern times, school space 
required specialized facilities for education and development of the new generation of children, which would be built as a full-fledged school, taking into account all the necessary hygienic standards.

Table 1. Typology of small-scale schools in Ukraine.

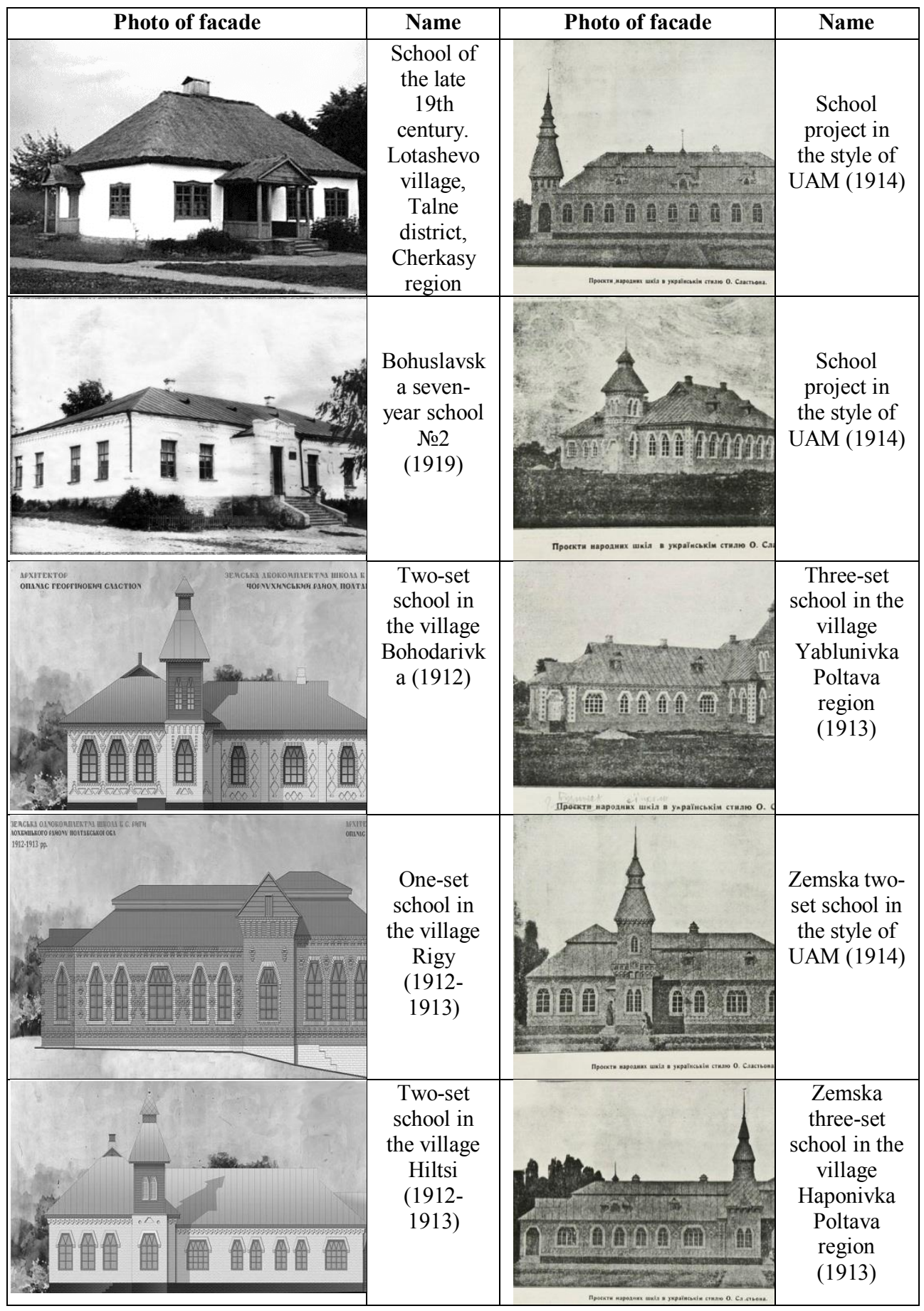


In 1905 there were more than 20 different types of schools operating in Ukraine, 1357 elementary schools, 130 secondary commercial schools, 33 women's high schools were opened. Some of those schools still exist, but the design of rural school buildings (despite some successful examples) was slow. Schools were divided into public and private, women's and men's, denominational and secular with different periods of studying. The educational schedule became more democratic.

Zemsky schools, which appeared in the territory of Ukraine after the foundation of zemstvo in 1864, operated in rural areas in zemsky provinces. Their activities were regulated by the "Regulations on Primary People's Schools" of 1864 and 1874. The schools were three-year educational establishments where children of all three years of studying (divided into three classes) were simultaneously engaged in one classroom with one teacher.

Educational institutions were generally divided into:

- one-set (elementary);

- two-set - in villages;

- three-set or three classes - in settlements and towns.

Studying was mainly provided in the native language in such schools.

- four-set, main and normal schools were established in cities;

- six-set - mainly gymnasiums.

Small-scale rural public schools prevailed in the hierarchy of educational institutions of the country Table 1 .

After the suppression of the revolution, all the achievements in the field of education were nullified: schools, libraries were closed, personnel of teachers was reviewed on the grounds of trustworthiness. In the late 90's two-set schools with 5 - 6 years of studying were opened. The network of vocational schools was expanded.

With the victory of the bourgeois-democratic revolution of $1910-1917$, the separation from the principles of traditional liberalism began in Mexico. After winning the revolution of 1910-1917, the first task was to develop a new constitution. Article 3 of the 1917 Political Constitution confirmed the basic principles of Mexican elementary school: compulsory, free, secular. Secular education envisaged education hostile to any religious teaching. The transition from "neutral secularity" (tolerance) to "combat secularity" was made [3].

A village school usually occupied one large room with approximately 40 children of both sexes and all ages. The term of studying was usually 4 years. In the evenings, the same school was attended by adults. People who had education of 6 years of elementary school taught there; most often people who could only read and write were sent to rural schools as teachers [4].

\section{Conclusion}

Public schools are institutions that have had significant impact on the level of education of Ukrainian and Mexican population in the countryside. The study of the typological features of the architecture of primary schools in the late XIX - early XIX centuries is an extremely important research. Leading architects of the time designed a large number of individual and typical public schools for small towns and villages in Ukraine. In the early XX century they were recognized as models of school construction and served as a typical analogue to such projects for the next 30 years. 
Table 2. Typology of small-scale schools in Mexico.

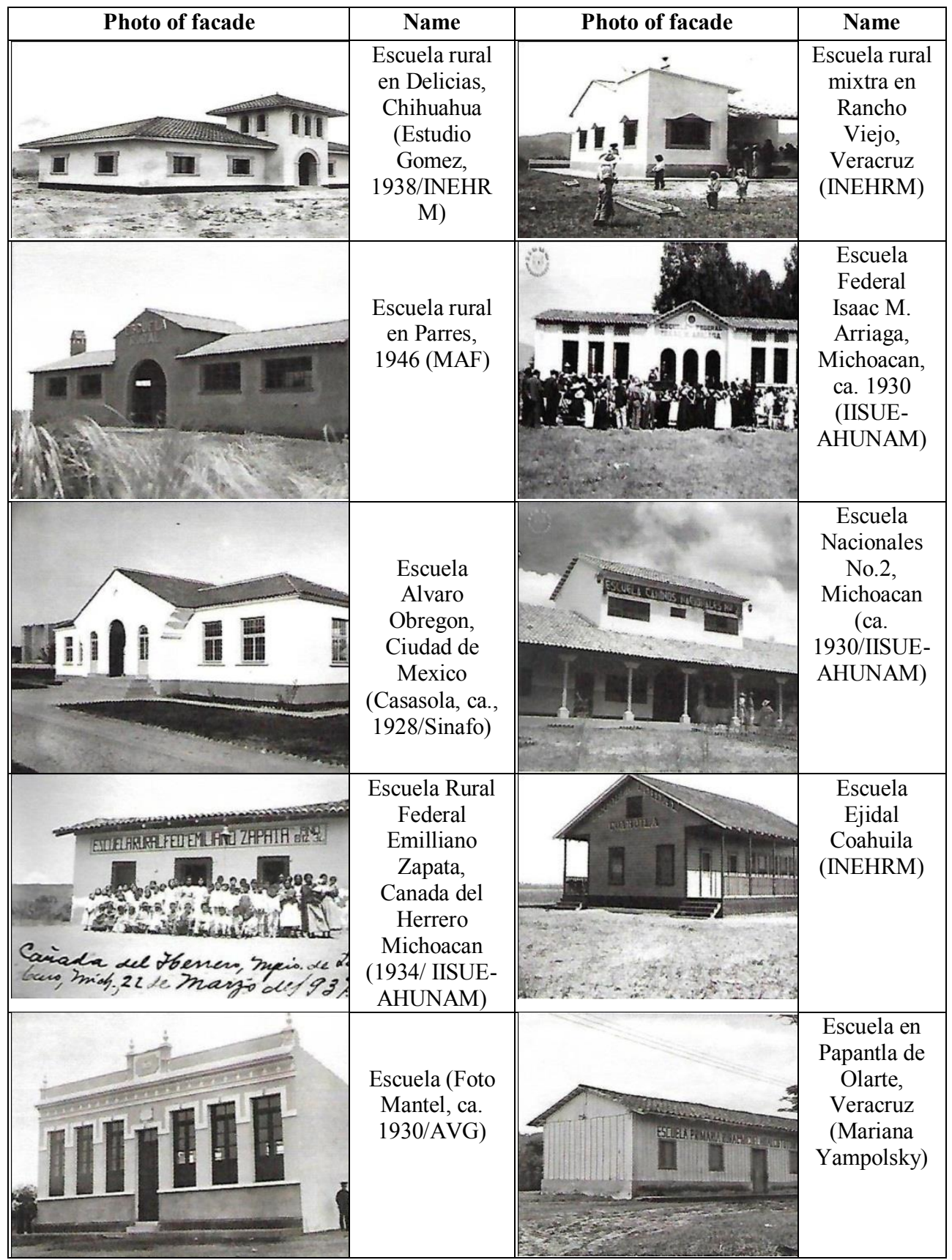


Table 3. Comparison of the school facades of Ukraine and Mexico at the end of XIX - beginning of XX centuries.

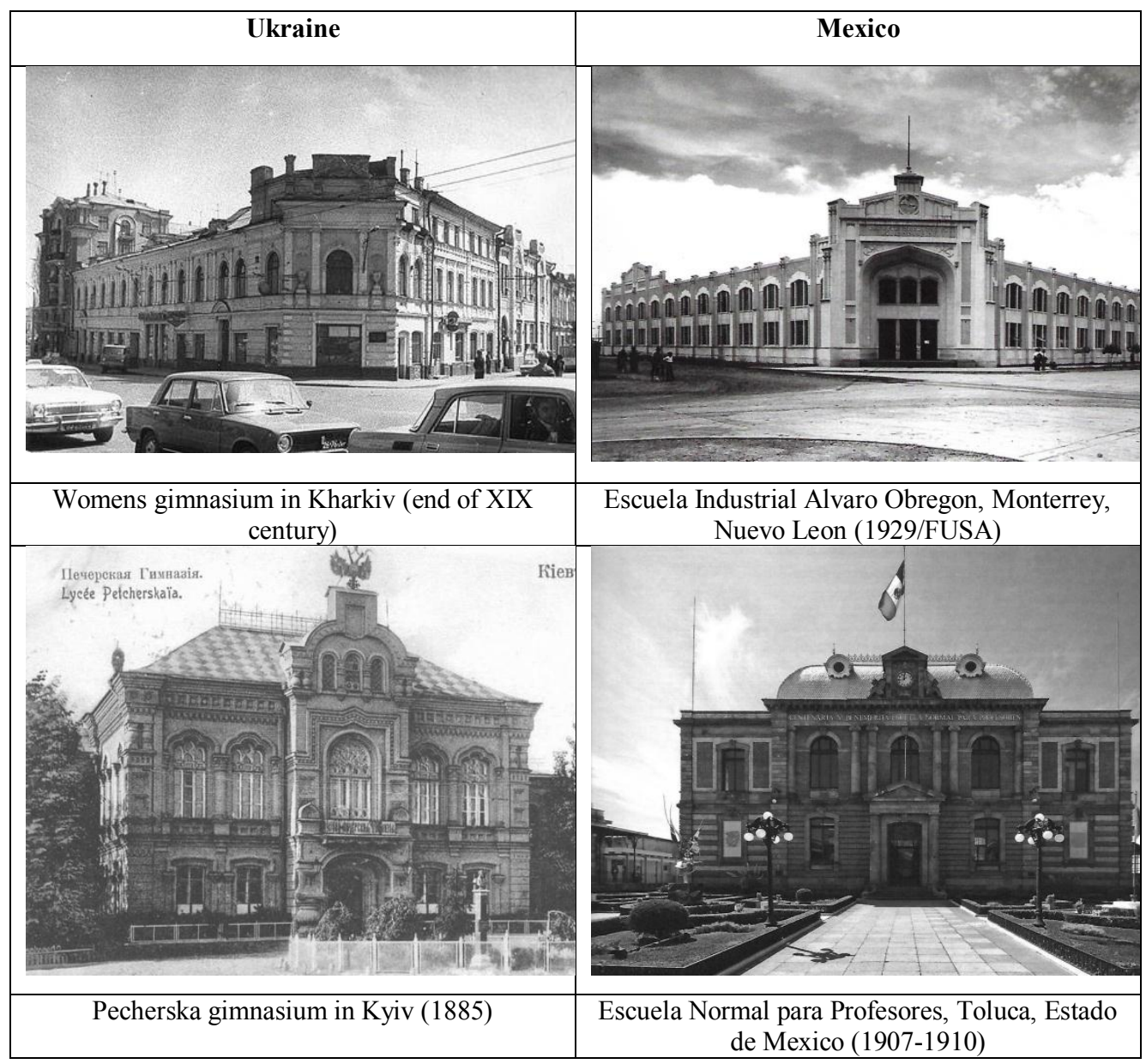

Massive construction of schools in Mexico began in the second half of the 1920s, as a part of the revolutionary educational program. During the Mexican Revolution, even the armed struggle and the lack of resources did not prevent Mexicans from working, albeit in isolation, in the construction of public educational institutions. The requirements, which were met by this new architecture, were significant advances in construction which addressed social needs through school buildings that allowed political action by the new regime. The new relevant system was formed in the context of the educational policy and the pedagogical program, which justified its use in the post-revolutionary Mexican movement. Therefore, the construction project took into account the needs of the working classes, agricultural and urban population.

Thus, it can be said that in the conditions of Ukraine and Mexico in the late XIX - early $\mathrm{XX}$ centuries the original types of school buildings formed, which are similar in the following ways:

- formed during the national revival movements;

- by types of school premises;

- by types of planning schemes;

- by size and shape of classrooms;

- by some elements of facade fragments; 
- by colours used in the facade.

Different in:

- geographical and climatic conditions;

- national character traits.

\section{Research perspectives}

This article can serve the development of education and architectural planning of the educational environment in the countryside. The factual and analytical materials, typological tables in this article and examples of projects by leading Ukrainian and Mexican architects can be useful in modern design or during the restoration of historical monuments of architecture of small schools.

\section{References}

1. A. Arano, National Council for Culture and the Arts (2011)

2. P. Alegna, Education in Mexico before and after the conquest (1963)

3. The population and housing censuses of 1895, 1900 and 1910 from which the illiteracy rate in Mexico was obtained are available on the website of the National Institute of Statistics and Geography. https://www.inegi.org.mx

4. F. Palavicini, The economic construction of schools, Mexico, Mexican Society of Geography and Statistics (1908)

5. H. Barnard, School Architecture (1970)

6. J. H. Wilkinson, From Brown to Bakke: The Supreme Court and School Integration: 1954-1978 (1979)

7. C. Rossell, W. D. Hawley, The Consequences of School Desegregation (1983)

8. J. Duffy, ed. C. E. Rosenberg, In Healing and History: Essays for George Rosen (1979)

9. J. T. Patterson, Brown v. Board of Education: A Civil Rights Milestone and Its Troubled Legacy (2001)

10. M. S. Hoffschwelle, Rebuilding the Rural Southern Community: Reformers, Schools, and Homes in Tennessee, 1900-1930 (1998)

11. D. Upton, Lancasterian, Journal of the Society of Architectural Historians 55, 238-253 (1996)

12. K. E. O'Rourke, Modern Architecture in Mexico City: History, Representation, and the Shaping of a Capital (2017)

13. R. Donato, The Other Struggle for Equal Schools: Mexican Americans During the Civil Rights Era (1997)

14. G. Orfield, M. Bachmeier, Equity and Excellence in Education 30, 5-23 (1997) 